\title{
A CLINICO-PATHOLOGICAL STUDY OF SQUAMOUS CELL CARCINOMA OF GINGIVOBUCCAL COMPLEX IN PUNJAB
}

\author{
Md. Khurshid Pervej ${ }^{1}$, Manjit Singh ${ }^{2}$, Baldev Singh 3 , Ramesh Kumar Kundal ${ }^{4}$, Anmol Singh ${ }^{5}$ \\ ${ }_{1}^{1}$ Senior Resident, Department of ENT, Malda Medical College, Malda, West Bengal, India. \\ ${ }^{2}$ Associate Professor, Department of ENT, GMC\&RH, Patiala, Punjab, India. \\ 3 Professor, Department of ENT, GMC \& RH, Patiala, Punjab, India. \\ 4 Professor and Head, Department of Pathology, GMC\&RH, Patiala, Punjab, India. \\ 5 MBBS Intern, GMCH, Sector 32, Chandigarh, Punjab, India.
}

\section{BACKGROUND}

\section{ABSTRACT}

Head and neck cancers are among the 10 most frequent cancers and are the sixth most common cancers worldwide. Among these cancers, oral cavity in general and gingivobuccal complex in particular is prone to a myriad of changes with advancing age as well as a result of environmental and lifestyle-related factors.

The objective of this study was to gain appreciation of the correlation of clinical presentation and habit patterns as well as to note the pathological differentiation and the TNM (Tumour, Node, Metastasis) classification of squamous cell carcinoma (SCC) of gingivobuccal complex in Punjab.

\section{MATERIALS AND METHODS}

This prospective study was conducted on 30 patients of diagnosed cases of SCC of the gingivobuccal complex in the Department of ENT and Department of Pathology of Government Medical College and Rajindra Hospital, Patiala, Punjab, India. The selected patients were those who reported a definitive history of ulcerative lesion of gingivobuccal complex. Detailed history of patients was taken and tumour data including site, subsite, grade and TNM stage were collected.

\section{RESULTS}

The mean age of the patients was $52.53 \pm 12.91$ years. There were $83.33 \%$ male and $16.67 \%$ female patients. The most common presenting symptoms of SCC of gingivobuccal complex were ulceration, pain and mass in the oral cavity (in all cases) followed by trismus. The most common substance abuse observed was tobacco use. The most common subsite of SCC of gingivobuccal complex was buccal mucosa. The majority of the patients presented in stages I and III (26.67\% each). SCC of the buccal mucosa was positively correlated with alcohol use, but the association was statistically non-significant $(\mathrm{r}=0.01)$, but it was positively correlated with smoking and tobacco use (in other form) and the correlation was statistically significant ( $\mathrm{r}=0.553$ and 0.517 ).

\section{CONCLUSION}

SCC of the retromolar trigone was positively correlated with alcohol, smoking and tobacco use (in other form) and the correlation was statistically significant.

\section{KEYWORDS}

Carcinoma, Gingivobuccal Complex, Alcohol Abuse, Smoking, Tobacco, Trismus.

HOW TO CITE THIS ARTICLE: Pervej MK, Singh M, Singh B, et al. A clinico-pathological study of squamous cell carcinoma of gingivobuccal complex in Punjab. J. Evolution Med. Dent. Sci. 2018;7(13):1602-1606, DOI: 10.14260/jemds/2018/363

\section{BACKGROUND}

Head and neck cancer (HNC) is a term used to describe malignant tumours originating in the upper aerodigestive tract including the oral cavity, larynx, pharynx and nasopharynx. Majority (90\%) of these cancers are squamous cell carcinomas (SCCs) arising from epithelial mucous membrane. ${ }^{[1]}$ HNCs are among the 10 most frequent cancers and are the sixth most common cancers worldwide. Incidence rate is more than twice as high in men and is showing an increase in most parts of the world.[2,3] Onset occurs in the late middle age with median age at diagnosis ranging from 55 to 67 years. Among these cancers, oral cavity in general and

'Financial or Other Competing Interest': None.

Submission 07-02-2018, Peer Review 25-02-2018,

Acceptance 27-02-2018, Published 26-03-2018.

Corresponding Author:

Dr. Manjit Singh,

Associate Professor,

Department of ENT,

GMC and RH, Patiala, Punjab.

E-mail: drmanjitsingh62@yahoo.com

DOI: $10.14260 /$ jemds $/ 2018 / 363$

\section{(c) $($ ) $\odot$}

gingivobuccal complex in particular is prone to a myriad of changes with advancing age as well as a result of the environmental and lifestyle-related factors. The prevalence of oral cancer, the eighth most common cancer worldwide, is particularly high among men. In India, the age-standardised incidence rate of oral cancer is 12.6 per 100,000 population. ${ }^{[4]}$ The gingivobuccal complex is composed of the buccal mucosa, gingivobuccal sulcus, lower gingiva of mandibular alveolus, upper gingiva of maxillary alveolus and retromolar trigone area. In the Indian subcontinent, India accounts for a sizeable chunk of HNCs with gingivobuccal complex being the most common subsite. Hence, this cancer is aptly called as an "Indian cancer."[5] Gingivobuccal complex cancer typically occurs at the age of above 50 years, although it may occur in the younger patients also, particularly when associated with the habit of betel-chewing.[6,7] Among the various aetiological agents implicated in association with this cancer, the use of tobacco and alcohol tops the list. The high frequency of the gingivobuccal complex cancer observed in India is due to the peculiar tobacco-chewing habit, which exposes the buccal mucosa to high dose of carcinogens. One of the popular forms of smokeless tobacco used in different 
parts of India is betel quid (pan or pan masala). Individuals who consume betel quid frequently have a preference regarding which side they chew the betel. This is corresponding to the site of tumour development. Painful or loose-fitting dentures have also been associated with gingivobuccal cancer.[8,9] In the early stages, cancers of the gingivobuccal complex appear either as raised, firm, pearly plaques or as irregular, roughened or verrucous areas of mucosal thickening, possibly mistaken for leukoplakia. As these lesions enlarge, they typically create ulcerated and protruding masses that have irregular and indurated (rolled) borders.[10] On histological examination these cancers begin as dysplastic lesions, which may or may not progress to fullthickness dysplasia (carcinoma-in-situ) before invading the underlying connective tissue stroma. SCCs range from welldifferentiated keratinising neoplasms to anaplastic, sometimes sarcomatoid tumours and from slowly to rapidly growing lesions. However, the degree of histologic differentiation as determined by the relative degree of keratinisation is not correlated with the behaviour. As a group, these tumours tend to infiltrate locally before they metastasise to other sites. The routes of extension depend on the primary site. The favoured sites of local metastasis are the cervical lymph nodes, whereas the most common sites of distant metastasis are mediastinal lymph nodes, lungs, liver and bones. Unfortunately, such distant metastases often occur at the time of discovery of the primary lesion.[10] Buccal carcinoma commonly presents as a slow-growing mass on the buccal mucosa with pain, ulceration or trismus. Maxillary alveolus or upper gingival cancer presents with pain, ulceration, loose teeth or poorly fitting dentures, and advanced disease may also present with infraorbital paraesthesia, trismus or nasal obstruction. The most common presenting symptom of the mandibular alveolus or lower gingival carcinoma is pain and it may also present with loosening of teeth and labial paraesthesia. The patients of gingivobuccal carcinoma in whom the retromolar trigone area is affected mainly present with pain, trismus, otalgia and lingual paraesthesia.[11-13]

\section{Aims and Objectives}

The Aims and Objective of the Present Study are as follows

- To study the correlation of clinical presentation and habit patterns in squamous cell carcinoma of gingivobuccal complex in Punjab.

- $\quad$ To note the pathological differentiation of squamous cell carcinoma of gingivobuccal complex in Punjab on HPE.

- To study the stage of TNM classification of squamous cell carcinoma of gingivobuccal complex at the time of presentation.

\section{MATERIALS AND METHODS}

This prospective study was conducted on 30 patients of diagnosed cases of SCC of the gingivobuccal complex in the Department of ENT and Department of Pathology of Government Medical College and Rajindra Hospital, Patiala, Punjab, India. To examine the relationship between SCC of gingivobuccal complex with the factors selected to be examined under the study so as to examine the strength and relationship (Person chi-square) was used as a statistical method.
The selected patients were those who reported a definitive history of ulcerative lesion of gingivobuccal complex. Detailed history of patient was taken, which included history of any occupational exposures to carcinogens/ toxins, environmental tobacco smoke exposure, personal health and family cancer. Tumour data including site, subsite, grade and TNM (Tumour, node, metastasis) stage were collected. Each patient was subjected to a detailed clinical examination, that is general physical examination, systemic examination and ENT examination including examination of oral cavity, oropharynx, anterior and posterior rhinoscopy. Also, neck examination was conducted for any enlarged lymph nodes. The patient was admitted to the ward. Biopsy was taken under local or general anaesthesia and the biopsy specimen taken was sent for histopathological examination. Proven cases of SCCs of gingivobuccal complex were taken up and reviewed to gather data on multiple clinico-pathological variables. Histopathological differentiation was noted. TNM staging of the disease was described. Data were statistically analysed using mean value, standard deviation and Pearson's ' $r$ ' correlation and the result was finally presented in tables and graphs.

The date has used "Pearson chi-square" for analysis and the ' $p$ ' value had been analysed (which was found to be significant at a value of $<0.05$, as shown in the table attached below. This analysis was performed with IBM SPSS 22 version.

\section{Inclusion Criteria}

1. Clinical suspicion of premalignant lesion and/or condition in the gingivobuccal complex.

2. Clinical and histopathologic diagnosis of gingivobuccal complex carcinoma.

3. No history of previous treatment.

\section{Exclusion criteria}

1. History of head and neck irradiation.

2. Present or previous history of immunosuppression (disease or treatment related).

3. Previous history of HNC.

4. Growth arising in the lip, tongue and hard palate.

5. Patient refusal.

\section{RESULTS}

This study was conducted on 30 diagnosed cases of SCC of gingivobuccal complex admitted in the Department of ENT, Government Medical College, Rajindra Hospital, Patiala. These cases were studied for age, sex distribution, role of aetiological factors and clinical presentation including site, subsite, TNM stage, histopathological grading as well as correlation of habit patterns with clinical presentation. The maximum number of cases of SCC of gingivobuccal complex were seen in fourth-sixth decade with peak in fourth decade (30\%) of life. Youngest in series were 21 years old and oldest 71 years old. Men were found to be predominantly affected in this study. There were $83.33 \%$ men and $16.67 \%$ women. The maximum number of cases of SCC of the gingivobuccal complex among both men and women was seen in fourthsixth decade with peak in the fourth decade $(23.33 \%)$ in case of men and $(6.67 \%)$ in case of women of life. Maximum number of cases were recorded among businessmen 
(23.33\%) followed by housewives and labourers $(13.33 \%$ each). The most common presenting symptoms of SCC of the gingivobuccal complex are ulceration, pain and mass in the oral cavity (in all cases) followed by trismus (80\%), neck swelling (53.33\%), loose teeth (50\%), dysphagia (40\%), otalgia $(36.67 \%)$, lingual paraesthesia $(30 \%)$, infraorbital paraesthesia (23.33\%) and nasal obstruction (10\%) (Fig. 3). In patients with SCC of gingivobuccal complex, the most common substance abuse was tobacco use (in any form, $70 \%$ ), whereas alcohol use and smoking were present in $63.33 \%$ and $33.33 \%$ cases respectively. The most common of subsite of SCC of gingivobuccal complex was buccal mucosa (73.33\%) followed by retromolar trigone (30\%) (Fig. 1), mandibular alveolus (26.67\%) and maxillary alveolus (20\%) (Fig. 2). In patients with SCC of gingivobuccal complex (53.33\%) cases were well differentiated; moderately differentiated SCC was seen in $30 \%$ cases; and poorly differentiated SCC was observed in $16.67 \%$ cases. Maximum number $(26.67 \%)$ of patients with SCC of the gingivobuccal complex presented in T1N0M0 followed by T3N1M0 (16.67\%). Least number of cases were in T1N1M0, T4N1M0 and T4N2M1 (3.33\% each) (Fig. 4). The majority of the patients presented in stage I and III (26.67\% each) followed by stage II $(20 \%)$ and stage IVA $(16.67 \%)$. Least number of patients presented in stage IVC $(10 \%)$. SCC of buccal mucosa was associated with alcohol use, but the association was statistically non-significant $\left(\mathrm{X}^{2}=1.03, \mathrm{p}=0.954\right)$. It was correlated with smoking and tobacco use (in other form) and the association was statistically significant $\left(\mathrm{X}^{2}=1.03, \mathrm{p}=\right.$ 0.001 and $\mathrm{X}^{2}=7.19, \mathrm{p}=0.013$ ). SCC of the retromolar trigone was positively associated with alcohol, smoking and tobacco use (in other form) and the association was statistically significant $\left(\mathrm{X}^{2}=5.06, \mathrm{p}=0.024 ; \mathrm{X}^{2}=6.43, \mathrm{p}=0.011\right.$; and $\left.\mathrm{X}^{2}=6.72, \mathrm{p}=0.002\right)$. SCC of the maxillary alveolus was positively associated with alcohol, smoking and tobacco use (in other form) and the association was statistically significant $\left(\mathrm{X}^{2}=8.47, \mathrm{p}=0.012 ; \mathrm{X}^{2}=6.28, \mathrm{p}=0.023\right.$; and $\mathrm{X}^{2}=11.53, \mathrm{p}=0.002$ ). SCC of the mandibular alveolus was positively associated with alcohol, smoking and tobacco use (in other form) and it was statistically significant $\left(\mathrm{X}^{2}=5.26\right.$, $\mathrm{p}=0.022 ; \mathrm{X}^{2}=5.59, \mathrm{p}=0.021 ;$ and $\mathrm{X}^{2}=8.47, \mathrm{p}=0.004$ ).

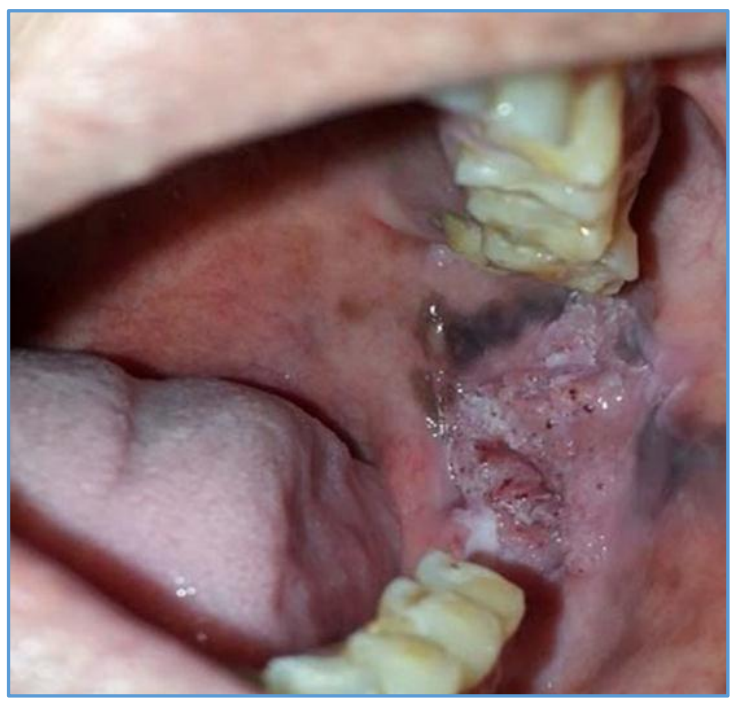

Figure 1. SCC of Retromolar Trigone

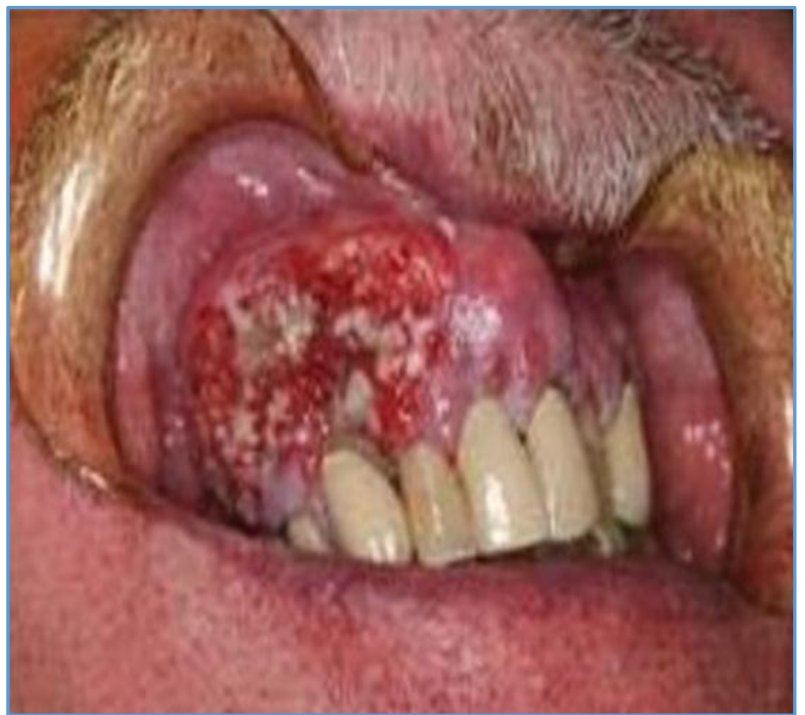

Figure 2. SCC of Upper Gingiva
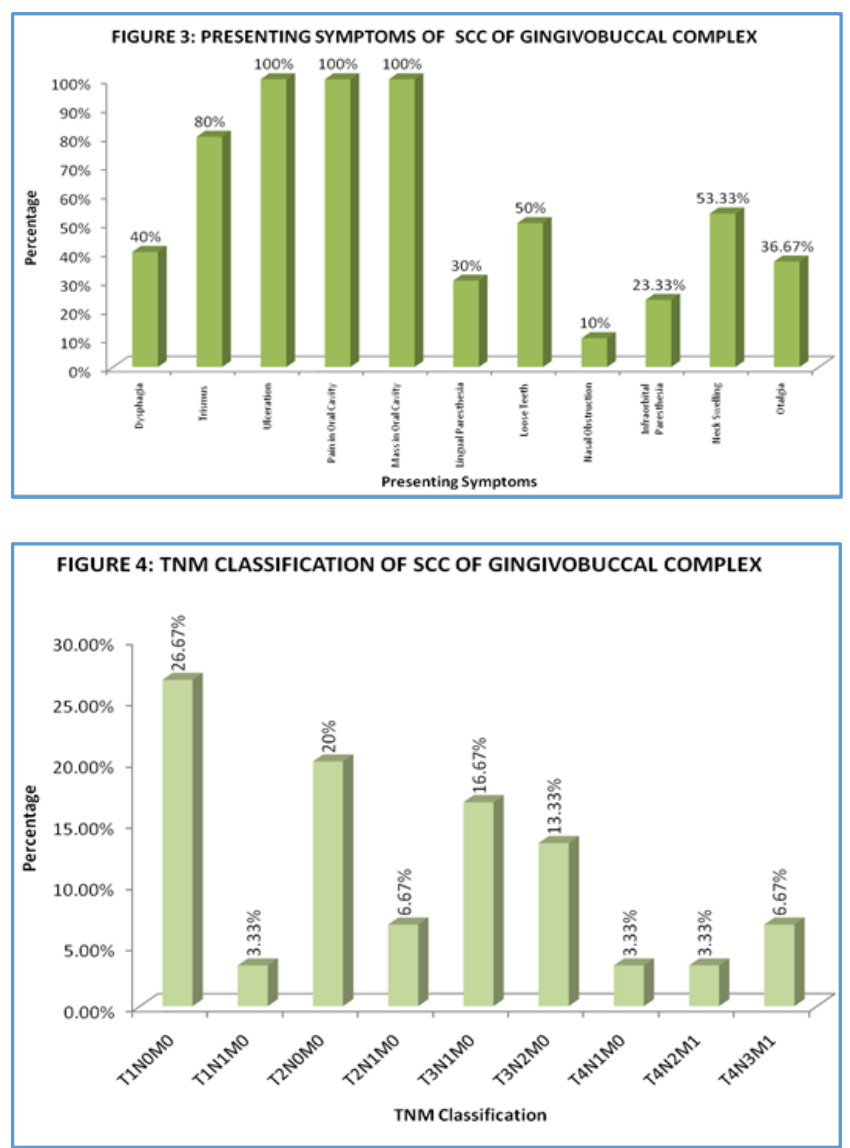

\section{DISCUSSION}

In this study, overall maximum age incidence of SCC of the gingivobuccal complex was seen from fourth to sixth decade with peak incidence in the fourth decade. Youngest in series were 21 years old and oldest 71 years old. In this study, the mean age of the patients at presentation was 52.53 years. Study is comparable with study of Nayak et al[14] and Lekawale et al.[15] From these studies, it is found that most of the SCCs of oral cancer patients present at fifth decade of age. In this study male-to-female ratio was $5: 1$, which is comparable with that in studies conducted by Iype et al[6] and Dewan et al.[16] In this study, the incidence of SCC of the gingivobuccal complex was recorded to be maximum in businessmen (23.33\%) followed by housewives and 
labourers (13.33\% each). The is compared with other similar studies.[17,18] The results of the study for the presenting symptoms of SCC of the gingivobuccal complex can be compared with those of the study conducted by Sharma et al.[19] This study found that the most common clinical symptom at presentation was oral ulcer (76\%), pain at local site (43\%) and swelling/ growth (33\%).[19] In the present study, the most common substance abuse was tobacco use (in any form other than smoking; 70\%) followed by alcohol abuse (63.33\%) and smoking (33.33\%). The results of the study can be compared with those of the study conducted by Sharma et al.[19] This study found that the most common substance abuse was tobacco chewing $(47 \%)$ followed by smoking (40\%) and alcohol (12\%). Another similar study was conducted by Kumar $\mathrm{V}$ et al, which reported that the most common form of substance abuse in patients with SCC of the gingivobuccal complex was smokeless tobacco (68.75\%) followed by smoking (39.58\%) and alcohol (12.5\%).[20] The study can be compared with a study conducted by Singh et al[18] regarding the most frequent subsite of SCC of the gingivobuccal complex. The study found that the most common site of oral cancer is buccal mucosa and gingivobuccal complex (43.8\%) followed by mandibular alveolus (32.1\%). Maxillary alveolus and retromolar trigone constituted $1.1 \%$ and $0.9 \%$ cases, respectively.[18] The study found that in $53.33 \%$ cases SCC was well differentiated and moderately differentiated SCC was seen in 30\% cases; and poorly differentiated SCC was found in $16.67 \%$ cases, which is comparable with the study conducted by Khandekar,[21] which reported $33.75 \%$ cases of well-differentiated, $27.5 \%$ cases of verrucous-differentiated, $20 \%$ cases of moderately differentiated and $18.75 \%$ cases of poorly differentiated oral cancers.[21] This study can be compared with that conducted by Sharma et al,[19] which reported that tumour size was $\mathrm{T} 1$ in 18\%, T2 in 59\%, T3 in 13\% and T4 in 10\% cases, whereas lymph node involvement was clinically absent in $33 \%$ of cases. In rest of the cases, clinical nodal staging was as follows: N1 16\%; N2 51\%; and N3 nil.[19] Another similar study conducted by Kruse et al,[22] which reported that tumour status of patients with oral SCC showed T1 in $35.82 \%$, $\mathrm{T} 2$ in $23.88 \%$, $\mathrm{T} 3$ in $4.47 \%$ and $\mathrm{T} 4$ in $35.82 \%$ cases whereas lymph node involvement was clinically absent in $70.14 \%$ of cases. In rest of the cases, clinical nodal staging was as follows: N1 16.41\%; N2 13.43\%; and N3 nil. Metastasis was absent in $85 \%$ of the cases.[22] This study is similar to that conducted by Mathur et al[23] regarding correlation of clinical presentation and habit patterns in SCC of the gingivobuccal complex. The study found that the habit of quid chewing was associated with all clinical patterns of the oral SCC, that is ulcerative, papillary, papillary infiltrative and ulcerative infiltrative. Usage of quid was also associated with infiltrative lesions than the combined habit of quid and smoking. Alcohol use alone was not seen in all patients. ${ }^{[23]}$ The study can be compared with a study conducted by Bhat et al,[24] which reported that patients who had the habit of chewing smokeless tobacco had lesions predominantly on the buccal mucosa followed by tongue. Those who only smoke had lesion commonly on the tongue. Smoking with consumption of alcohol was the most common combination observed, and these patients had lesions commonly on the tongue base and tonsils followed by oral tongue and buccal mucosa. [24]

\section{CONCLUSION}

Patients with SCC of the gingivobuccal complex are more likely to be middle-aged men. Furthermore, this study suggests that SCCs of retromolar trigone, maxillary alveolus and mandibular alveolus are positively correlated with smoking and tobacco use (in any other form) and the correlation is statistically significant. Whereas in SCC of buccal mucosa, smoking and tobacco use (in any other form) has a positive correlation which is statistically significant, a statistically non-significant correlation was found for alcohol consumption. Majority of the patients had either welldifferentiated or moderately differentiated cancer on histopathological examination. The majority of the patients presented in stages I and III followed by stage II and stage IVA. We also acknowledged some limitations to this study. One limitation of the study was a relatively small patient cohort.

\section{REFERENCES}

[1] Parkin DM, Bray F, Ferlay J, et al. Global cancer statistics, 2002. CA Cancer J Clin 2005;55(2):74-108.

[2] Atri R, Dhankar R, Nair V, et al. Management of radiation induced xerostomia in head and neck cancers. J Oral Health Comm Dent 2007;1(2):33-9.

[3] Jemal A, Bray F, Center MM, et al. Global cancer statistics. CA Cancer J Clin 2011;61(2):69-90.

[4] Petersen PE. Strengthening the prevention of oral cancer: The WHO perspective. Community Dent Oral Epidemiol 2005;33(6):397-9.

[5] Bhat M, Rao VV, D'souza C, et al. Gingivo-buccal cancer: an institutional experience of 100 patients. J Evol Med Dent Sci 2014;3(48):11578-84.

[6] Iype EM, Pandey M, Matthew A, et al. Squamous cell cancer of buccal mucosa in young adults. Br J Oral Max Surg 2004;42(3):185-9.

[7] Lee JJ, Jeng $\mathrm{JH}$, Wang $\mathrm{HM}$, et al. Univariate and multivariate analysis of prognostic significance of betel quid chewing in squamous cell carcinoma of buccal mucosa in Taiwan. J Surg Oncol 2005;91(1):417.

[8] Velly AM, Franco EL, Schlecht N, et al. Relationship between dental factors and risk of upper aerodigestive tract cancer. Oral Oncol 1998;34(4):284-91.

[9] Young TB, Ford CN, Brandenburg JH. An epidemiologic study of oral cancer in a statewide network. Am J Otolaryngol 1986;7(3):200-8.

[10] Kumar R, Abbas AK, Fausto N, et al. Pathologic basis of disease. $8^{\text {th }}$ edn. Philadelphia, PA: Saunders Elsevier 2010.

[11] Browning GG, Burton MJ, Clarke R, et al. Scott-Brown's otorhinolaryngology, head and neck surgery. $7^{\text {th }}$ edn. UK: Hodder Arnold 2008.

[12] Byers RM, Anderson B, Schwarz EA, et al. Treatment of squamous carcinoma of the retromolar trigone. Am J Clin Oncol 1984;7(6):647-52.

[13] Genden EM, Ferlito A, Shaha AR, et al. Management of cancer of the retromolar trigone. Oral Oncol 2003;39(7):633-7.

[14] Nayak VN, Donoghue M, Selvamani M. Oral squamous cell carcinoma: a 5 years institutional study. J Med Radiol Pathol Surg 2015;1:3-6. 
[15] Lekawale H, Raikwar KR, Ghodke $M$, et al. Postoperative morbidity in squamous cell carcinoma of oral cavity. Ind J App Res 2016;6(2):528-31.

[16] Dewan AK, Dabas SK, Pradhan T, et al. Squamous cell carcinoma of the superior gingivo-buccal sulcus: an 11-year institutional experience of 203 cases. Jpn J Clin Oncol 2014;44(9):807-11.

[17] Ganesh R, John J, Saravanan S. Sociodemographic profile of oral cancer patients residing in Tamil Nadu-a hospital-based study. Ind J Cancer 2013;50(1):9-13.

[18] Singh MP, Misra S, Rathanaswamy SP, et al. Clinical profile and epidemiological factors of oral cancer patients from North India. Natl J Maxillofac Surg 2015;6(1):21-4.

[19] Sharma RG, Bang B, Verma H, et al. Profile of oral squamous cell cancer in a tertiary level medical college hospital: a 10 year study. Indian J Surg Oncol 2012;3(3):250-4.
[20] Kumar V, Sindhu VA, Rathanaswamy S, et al. Cancers of upper gingivo-buccal sulcus, hard palate and maxilla: a tertiary care centre study in North India. Natl J Maxillofac Surg 2013;4(2):202-5.

[21] Khandekar SP, Bagdey PS, Tiwari RR. Oral cancer and some epidemiological factors: a hospital based study. Ind J Com Med 2006;31:157-9.

[22] Kruse AL, Bredell M, Grätz KW. Oral squamous cell carcinoma in non-smoking and non-drinking patients. Head Neck Oncol 2010;2:24.

[23] Mathur PT, Dayal PK, Pai KM. Correlation of clinical patterns of oral squamous cell carcinoma with age, site, sex and habits. J Ind Acad of Oral Med Radiol 2011;23(2):81-5.

[24] Bhat SP, Bhat V, Permi H, et al. Oral and oropharyngeal malignancy: a clinicopathological study. Int J Pathol Lab Med 2015;1(1):0A1. 